\title{
Process Parametric Optimization of CNC Vertical Milling Machine Using Taguchi Technique in Varying Condition
}

\author{
Piyush pandey*, Prabhat kumar sinha, Vijay kumar, Manas tiwari \\ Mechanical Engineering Department, Sam Higginbottom Institute of Agriculture Technology and sciences, \\ Allahabad
}

\begin{abstract}
An experiment was conducted to perform the parametric optimization of CNC end milling machine tool in varying condition. The tool used for experiment was of Solid Carbide and the Mild Steel work piece was used during experiment. The experiment has been taken place efficiently and completes its all objective of optimization. The practical result can be used in industry to get the desirable Surface Roughness and Material Removal Rate for the work piece by using suitable parameter combination.
\end{abstract}

\section{Introduction}

The Taguchi's method for optimization has been used as the principle of the process. It helps in the selection of experiment process, selection of orthogonal array, process of reducing variation, tolerance design, analysis and confirmation test [1]. The Taguchi's design is an efficient method which can optimize given various control and noise factor using fewer resources and factorial design. This study includes feed rate spindle speed and depth of cut as a control factor and as a noise factors were the operating chamber temperature and the usage the different tool insert in the same specification which introduce tool condition and dimensional variability [2]. The optimization of feed rate is essential in terms of providing high precision and efficient machining. The surface roughness is very sensitive to the feed rate. The effect of insert run out error and the variation of feed rate on the surface roughness and the dimensional accuracy in milling operation using a surface roughness model. The estimated surface roughness value, the optimal feed rate that give a maximum material removal rate under given surface roughness constraint could be selected by bisectional method [3]. By validating the result and performance of Taguchi Method a group of researchers study the role of parameter design and Taguchi's methodology for implementing it. It include the importance of variation reduction, the use of noise factors, the role of interaction, selection of quality characteristic, signal to noise ratios, experimental strategy dynamic systems, and applications [4]. A design of experiment (DOE) has been implemented to select manufacturing process parameter for quality of the work piece. There use of two different parameter Dependent and independent has been considered for optimization. The Dependent parameters were material removal rate and surface roughness. The independent parameters used were Rake Angle, Helix Angle, Cutting Speed and Depth of cut. The experiment was conducted in various steps by selection of quality characteristics, noise factors, control factors, orthogonal array and then conducting and confirming experiment. The L18 was used since it has seven three level column and one two level column [5]. The deviation of quality characteristics from the target causes loss. The uncontrollable factor which causes the characteristics to deviate from the target values are called noise factors. Signal-to-noise $(\mathrm{S} / \mathrm{N})$ ratio was used as a measurable value instead of standard deviation because as the mean decreases, the standard deviation decreases and vice versa [6]. To increase the process efficiency, flexibility and robustness, Taguchi dynamic approach couple with a proposed ideal function model for high dimensional quality. To increase the robustness of the manufacturing process, the experiment was design to consider the effect of manufacturing noise and to compound them as to extreme condition for assessing the quality characteristics of the work piece [7]. To maintain stable machining much attention was given to the formation of desired chip and chip control to facilitate its easy removal, Chip formation and breaking aspect perform significant role in machining. Problem with surface finish, work piece accuracy and tool life can be caused by minor changes in the chip formation process [8]. Quality improvement program in milling industry central composite designs and classical fractional factorial design were used in conjunction with the philosophy given by Taguchi [9]. ANOVA or analysis of variance used for analyzing and interpreting the experimental results, It include the F-Test and percentage contribution method which helps in the statistical test of comparison of result. ANOVA was applied to the orthogonal array types of designed experiment [1]. In end milling operation to assure product quality and increased production rate Artificial Neural Networks (ANN) model was developed. In this system the accelerometer and a proximity sensor were used during cutting to collect the vibration and rotation data respectively. Using Spindle Speed, Feed rate and Depth of cut which has a accuracy rate of (96-99\%) [10]. The Orthogonal array which was the systematic tabulated arrangement made from the combination of factor and levels helps the result to interpret properly. The uses of MINITAB made it 
possible to analyze and simulate the result in short span of time, MINITAB assist in analyze the work piece optimization's result.

\section{Experimental Setup}

There are 3 Solid Carbide Tools which are to be placed on to the CNC Milling machine as per the signified table of trials

\begin{tabular}{|c|c|c|}
\hline Tool Diameter $(\mathrm{mm})$ & Helix Angle $\left(^{\circ}\right)$ & Rake Angle $\left(^{\circ}\right)$ \\
\hline 8 & 35 & 4 \\
\hline 10 & 30 & 7 \\
\hline 12 & 45 & 10 \\
\hline
\end{tabular}

Rake angle

\section{Tool Specification}

Rake angle is used for better surface finish. The formal definition of a rake angle is "the angle between the leading edge of a cutting tool and a perpendicular to the surface being cut".
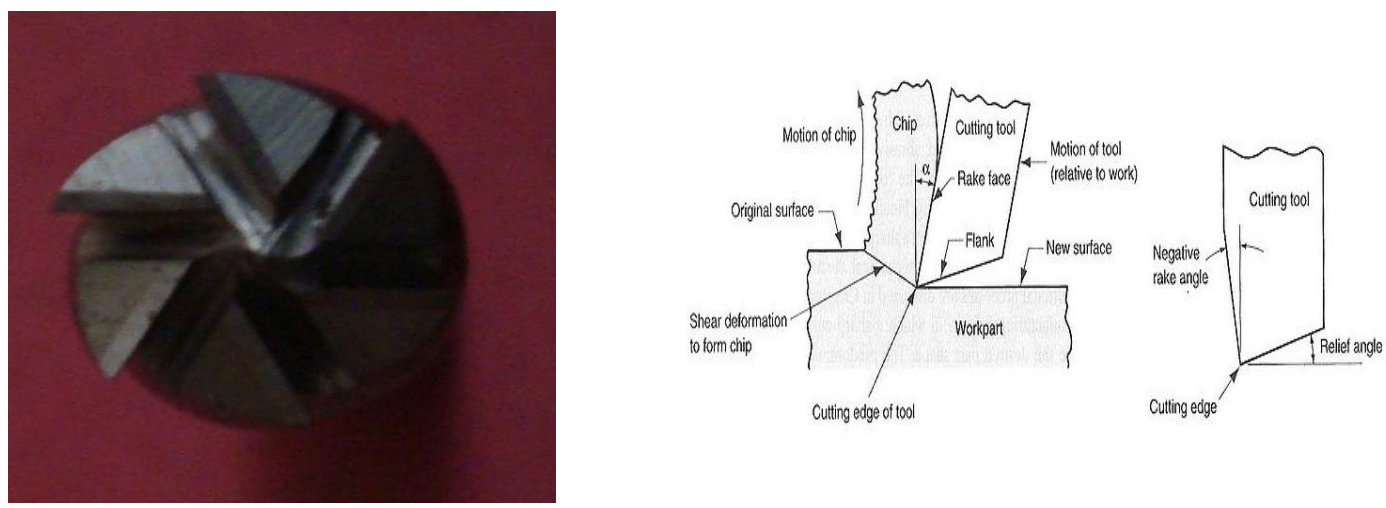

Rake Angle Representation

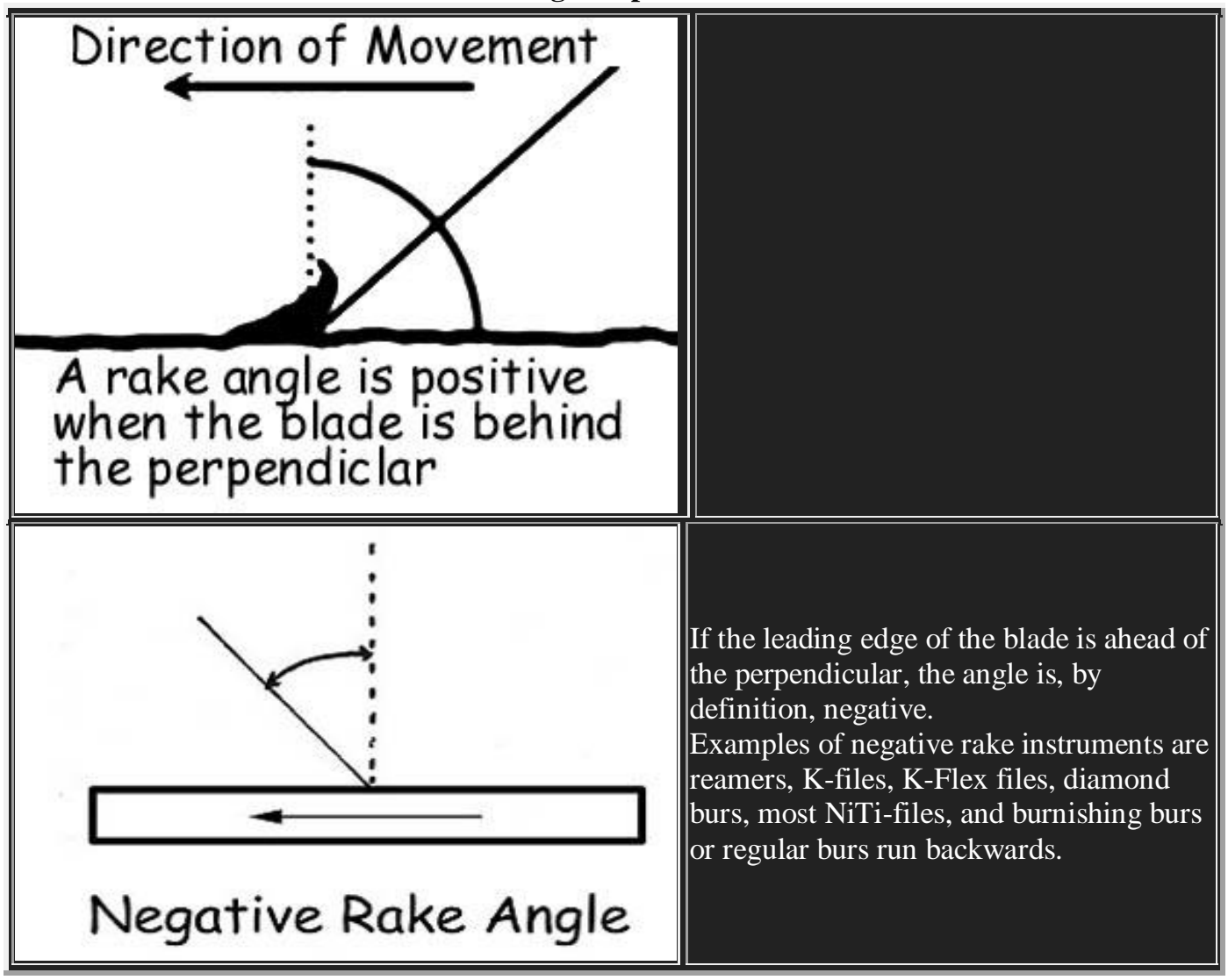




\section{Work piece Material}

\section{Rake Angle Importance}

We are using mild steel as a work piece. In this study mild steel having composition $(0.16-0.29 \%$ carbon is used. The density of mild steel is approximately $7.85 \mathrm{~g} / \mathrm{cm} 3$, Young's modulus is $210,000 \mathrm{MPa}$ $(30,000,000$ psi). Mild steel work piece having dimension L, B, W in mm. (respectively 39.4, 35, and 11.7) is used. Mild steel has a relatively low tensile strength, but it is cheap and malleable; surface hardness can be increased through carburizing.

\section{Control Parameters}

Coolant:A coolant is a fluid which flows through a device to prevent its overheating, transferring the heat produced by the device to other devices that use or dissipate it.

Cutting Oil arrangement have to be made in the machine. Cutting oil is water soluble with refractive index of 1.534 (Coolage SL non EP-Type). When a $10 \mathrm{ml}$ of oil is mixed with $50 \mathrm{ml}$ water a change of 0.1 comes in the refractive index.

\begin{tabular}{|c|c|c|c|}
\hline Depth of cut $(\mathrm{mm})$ & 0.6 & 0.7 & 0.8 \\
\hline Feed Rate $(\mathrm{mm} / \mathrm{min})$ & 100 & 110 & 150 \\
\hline Cutting Speed $(\mathrm{rm})$ & 800 & 900 & 1000 \\
\hline & $R P M=\frac{k \times \text { Speed }}{\text { Diameter }}$
\end{tabular}

e.g. for a cutting speed of $100 \mathrm{ft} / \mathrm{min}$ (a plain HSS steel cutter on mild steel) and diameter of 10 inches (the cutter or the work piece)

$$
\begin{gathered}
R P M=\frac{\text { Speed }}{\text { Circumference }} \\
F R=R P M \times T \times C L
\end{gathered}
$$

Following Steps Have to Be Undertaken-

There are 3 Solid Carbide Tools which are to be placed on to the CNC Milling machine as per the signified table of trials.

\begin{tabular}{|c|c|c|}
\hline Tool Diameter $(\mathrm{mm})$ & Helix Angle $\left(^{\circ}\right)$ & Rake Angle $\left(^{\circ}\right)$ \\
\hline 8 & 35 & 4 \\
\hline 10 & 30 & 7 \\
\hline 12 & 45 & 10 \\
\hline
\end{tabular}

Tool Specification

Cutting Oil arrangement has to be made in the machine. Cutting oil is water soluble with refractive index of 1.534(Cool age SL non EP-Type).When a $10 \mathrm{ml}$ of oil is mixed with $50 \mathrm{ml}$ water a change of 0.1 comes in the refractive index.

Defined levels are being made-

\begin{tabular}{|l|l|l|l|}
\hline Controllable Factors & Level 1 & Level 2 & Level 3 \\
\hline Cutting Speed (rpm) & 800 & 900 & 1000 \\
\hline Depth of cut (mm) & 0.6 & 0.7 & 0.8 \\
\hline Feed Rate $(\mathrm{mm} / \mathrm{min})$ & 100 & 110 & 150 \\
\hline Tool Diameter $(\mathrm{mm})$ & 8 & 10 & 12 \\
\hline Coolant & $\mathrm{C} 1$ & $\mathrm{C} 2$ & $\mathrm{C} 3$ \\
\hline
\end{tabular}

\section{Defined Levels Of factors}

Below we have taken the response table of the material removal rate(MRR) and the surface roughness(SR). Now out of 8 factors we have taken the factors from A to E because one of them which is A(coolant) is having 
just 2 levels and as prescribed in the Minitab software the minimum factor table which could accommodate 1 factor of 2 levels is L18 TABLE as in Taguchi designs.

The S/N ratio can be calculated as a logarithmic transformation of the loss function as shown below.

$\mathrm{S} / \mathrm{N}$ ratio for $\mathrm{MRR}=$

$$
\begin{aligned}
\mathrm{S} / \mathrm{N} \text { ratio for } \mathrm{SR}= & -10 \log \left(\frac{1}{n} \sum_{i=1}^{n} \frac{1}{y^{2} M R R}\right) \\
& -10 \log \left(\frac{1}{n} \sum_{i=1}^{n} y^{2} S R\right)
\end{aligned}
$$

The experimental results (or data) are further transformed into a signal-to-noise $(\mathrm{S} / \mathrm{N})$ ratio. There are several $\mathrm{S} / \mathrm{N}$ ratios available depending on the type of characteristic; lower is better (LB), Normal is best (NB) and higher is better $(\mathrm{HB})$

The characteristic that higher value represents better machining performance, such as MRR, is called 'Higher is better (HB)'. The characteristic that lower value represents better machining performance such as 'surface roughness, is called 'Lower is better (LB)'. Therefore, "HB" for MRR and "LB" for SF were selected

\begin{tabular}{|c|c|c|c|c|c|c|c|c|c|c|c|c|c|}
\hline \multirow[t]{2}{*}{ S.NO } & \multirow[t]{2}{*}{$\begin{array}{c}\text { (Milling } \\
\text { Type) }\end{array}$} & \multirow{2}{*}{$\begin{array}{c}\text { A } \\
\text { (Depth } \\
\text { of cut) } \\
(\mathrm{mm})\end{array}$} & \multirow{2}{*}{$\begin{array}{c}\text { B } \\
\text { (Cutting } \\
\text { Speed ) } \\
\text { (rpm) }\end{array}$} & \multirow{2}{*}{$\begin{array}{c}\mathrm{C} \\
\text { (Feed } \\
\text { rate) } \\
\text { mmpm }\end{array}$} & \multirow{2}{*}{$\begin{array}{c}\text { D } \\
\text { (Tool } \\
\text { Dia.) } \\
\text { mm }\end{array}$} & \multirow[t]{2}{*}{$E$} & \multirow[t]{2}{*}{$\mathrm{F}$} & \multirow[t]{2}{*}{$\mathrm{G}$} & \multirow[t]{2}{*}{ MRR } & \multirow[t]{2}{*}{$\begin{array}{l}\mathrm{S} / \mathrm{N} \\
\text { ratio }\end{array}$} & \multicolumn{3}{|c|}{$\begin{array}{c}\text { SR } \\
\text { Measurement times } \\
(\mu \mathrm{m})\end{array}$} \\
\hline & & & & & & & & & & & 1 & 2 & 3 \\
\hline 1 & 1 & 0.6 & 800 & 100 & 8 & 1 & 1 & 1 & 0.010 & -40.00 & 1.13 & 1.02 & 0.77 \\
\hline 2 & 1 & 0.6 & 900 & 110 & 10 & 2 & 2 & 2 & 0.014 & -37.07 & 0.93 & 0.86 & 1.53 \\
\hline 3 & 1 & 0.6 & 1000 & 120 & 12 & 3 & 3 & 3 & 0.127 & -17.92 & 2.12 & 1.12 & 1.43 \\
\hline 4 & 1 & 0.7 & 800 & 100 & 10 & 2 & 3 & 3 & 0.122 & -18.27 & 2.01 & 1.1 & 1.05 \\
\hline 5 & 1 & 0.7 & 900 & 110 & 12 & 3 & 1 & 1 & 0.024 & -32.39 & 1.5 & 2.09 & 2.06 \\
\hline 6 & 1 & 0.7 & 1000 & 120 & 8 & 1 & 2 & 2 & 0.402 & -7.91 & 1.01 & 1.1 & 0.97 \\
\hline 7 & 1 & 0.8 & 800 & 110 & 8 & 3 & 2 & 3 & 0.235 & -12.57 & 1.96 & 1.42 & 1.48 \\
\hline 8 & 1 & 0.8 & 900 & 120 & 10 & 1 & 3 & 1 & 0.021 & -33.55 & 1.39 & 0.98 & 1.91 \\
\hline 9 & 1 & 0.8 & 1000 & 100 & 12 & 2 & 1 & 2 & 0.107 & -19.41 & 2.22 & 2.42 & 1.57 \\
\hline 10 & 2 & 0.6 & 800 & 120 & 12 & 2 & 2 & 1 & 0.027 & -31.37 & 1.35 & 1.24 & 0.94 \\
\hline 11 & 2 & 0.6 & 900 & 100 & 8 & 3 & 3 & 2 & 0.052 & -25.67 & 0.92 & 0.82 & 1.01 \\
\hline 12 & 2 & 0.6 & 1000 & 110 & 10 & 1 & 1 & 3 & 0.357 & -8.94 & 0.94 & 0.98 & 2.01 \\
\hline 13 & 2 & 0.7 & 800 & 110 & 12 & 1 & 3 & 2 & 0.246 & -12.18 & 1.3 & 1.69 & 1.57 \\
\hline 14 & 2 & 0.7 & 900 & 120 & 8 & 2 & 1 & 3 & 0.121 & -18.34 & 1.14 & 1.58 & 1.35 \\
\hline 15 & 2 & 0.7 & 1000 & 100 & 10 & 3 & 2 & 1 & 0.277 & -11.15 & 1.43 & 2.7 & 1.25 \\
\hline 16 & 2 & 0.8 & 800 & 120 & 10 & 3 & 1 & 2 & 0.152 & -16.36 & 3.05 & 1.44 & 1.53 \\
\hline 17 & 2 & 0.8 & 900 & 100 & 12 & 1 & 2 & 3 & 0.022 & -33.15 & 1.87 & 2.81 & 2.31 \\
\hline 18 & 2 & 0.8 & 1000 & 110 & 8 & 2 & 3 & 1 & 0.357 & -8.94 & 1.98 & 2.69 & 3.09 \\
\hline
\end{tabular}
for obtaining optimum machining performance characteristics

\section{MRR (SECTION)}

\section{Experimental Values}

1. Average effect response table for raw data (MRR)

\begin{tabular}{|l|l|l|l|l|}
\hline LEVELS & $\mathrm{A}$ & $\mathrm{B}$ & $\mathrm{C}$ & $\mathrm{D}$ \\
\hline 1 & 0.097 & 0.136 & 0.098 & 0.196 \\
\hline 2 & 0.198 & 0.042 & 0.205 & 0.157 \\
\hline 3 & 0.149 & 0.271 & 0.141 & 0.123 \\
\hline MAX-MIN & 0.101 & 0.229 & 0.107 & 0.073 \\
\hline RANK & 3 & 1 & 2 & 4 \\
\hline
\end{tabular}


Average Effect Response Table for MRR

2. Average effect response table for $\mathrm{S} / \mathrm{N}$ ratios (MRR)

\begin{tabular}{|l|l|l|l|l|}
\hline LEVELS & A & B & C & D \\
\hline 1 & -26.82 & -20.84 & -24.60 & -18.90 \\
\hline 2 & -16.70 & -27.24 & -9.95 & -20.89 \\
\hline 3 & -20.70 & -12.43 & -20.90 & -24.40 \\
\hline MAX-MIN & 10.12 & 14.81 & 14.65 & 5.50 \\
\hline RANK & 3 & 1 & 2 & 4 \\
\hline
\end{tabular}

SR (SECTION)

Average Effect Response Table for S/N Ratios (MRR)

1. Next table shows the response values of the surface roughness (SR) column.

\begin{tabular}{|c|c|c|c|c|c|}
\hline \multirow{2}{*}{ S.NO } & \multicolumn{3}{|c|}{ Response values } & \multicolumn{1}{c|}{$\begin{array}{c}\text { Average } \\
\text { Value }(\mu \mathrm{m})\end{array}$} & \\
\cline { 2 - 4 } & 1 & 2 & 3 & 0.97 & 0.26 \\
\hline 1 & 1.13 & 1.02 & 0.77 & 1.10 & -0.82 \\
\hline 2 & 0.93 & 0.86 & 1.53 & 1.55 & -3.80 \\
\hline 3 & 2.12 & 1.12 & 1.43 & 1.38 & -2.79 \\
\hline 4 & 2.01 & 1.1 & 1.05 & 1.88 & -5.48 \\
\hline 5 & 1.5 & 2.09 & 2.06 & 1.02 & -0.17 \\
\hline 6 & 1.01 & 1.1 & 0.97 & 1.62 & -4.19 \\
\hline 7 & 1.96 & 1.42 & 1.48 & 1.42 & -3.04 \\
\hline 8 & 1.39 & 0.98 & 1.91 & 2.07 & -6.31 \\
\hline 9 & 2.22 & 2.42 & 1.57 & 1.17 & -1.36 \\
\hline 10 & 1.35 & 1.24 & 0.94 & 0.91 & 0.81 \\
\hline 11 & 0.92 & 0.82 & 1.01 & 1.31 & -2.34 \\
\hline 12 & 0.94 & 0.98 & 2.01 & 1.52 & -3.63 \\
\hline 13 & 1.3 & 1.69 & 1.57 & 1.35 & -2.60 \\
\hline 14 & 1.14 & 1.58 & 1.35 & 1.79 & -5.05 \\
\hline 15 & 1.43 & 2.7 & 1.25 & 2.00 & -6.02 \\
\hline 16 & 3.05 & 1.44 & 1.53 & 2.33 & -7.34 \\
\hline 17 & 1.87 & 2.81 & 2.31 & 2.58 & -8.23 \\
\hline 18 & 1.98 & 2.69 & 3.09 & & \\
\hline
\end{tabular}

\section{Response Values for SR}

1. Average effect response table for raw data (SR)

\begin{tabular}{|c|c|c|c|c|}
\hline LEVELS & $\mathrm{A}$ & $\mathrm{B}$ & $\mathrm{C}$ & $\mathrm{D}$ \\
\hline 1 & 1.16 & 1.44 & 1.24 & 1.40 \\
\hline 2 & 1.49 & 1.49 & 1.66 & 1.50 \\
\hline 3 & 2.00 & 1.72 & 1.41 & 1.75 \\
\hline MAX-MIN & 0.84 & 0.28 & 0.42 & 0.35 \\
\hline RANK & 1 & 4 & 2 & 3 \\
\hline
\end{tabular}

Average Effect Response Table for SR

2. Average effect response table for $\mathrm{S} / \mathrm{N}$ ratios $(\mathrm{SR})$

\begin{tabular}{|c|c|c|c|c|}
\hline LEVELS & A & B & C & D \\
\hline 1 & -1.20 & -2.95 & -3.40 & -2.62 \\
\hline 2 & -3.28 & -3.07 & -4.11 & -3.34 \\
\hline 3 & -5.58 & -4.31 & -2.28 & -4.23 \\
\hline MAX-MIN & 4.38 & 1.36 & 1.83 & 1.61 \\
\hline RANK & 1 & 4 & 2 & 3 \\
\hline
\end{tabular}

\section{Average Effect Response Table for S/N Ratios (SR)}

\subsection{Plotting methods}

The plotting of experimental results should be done in as many ways as are meaningful:

1. By levels of influential factors

2. By levels of combinations of influential factors to assess interaction possibilities

3. By order of actual test 
The column effects, and later ANOVA, indicate what to plot. To plot the effect of influential factors, the average result for each level must be calculated first. The sum of the data associated with each level in the OA column divided by the number of tests (data points) for that level will provide the appropriate averages. This applies to factors two or more levels.

Plot may be made with equal increments between levels on the horizontal axes of the graphs to show the relative strengths of the factors. The factors strength is directly proportional to the slope of the graph. An actual scale may also be used for the horizontal axes of continuous factors to graphically interpolate or extrapolate for prediction of other levels. With the actual scale, however the relative comparison of slopes is not meaningful.

The analysis was made using the popular software specifically used for design of experiment applications known as MINITAB 14. Before any attempt is made to use this simple model as a predictor for the measures of performance, the possible of interactions between the factors must be considered. Thus factorial design incorporates a simple means of testing for the presence of the interaction effects.

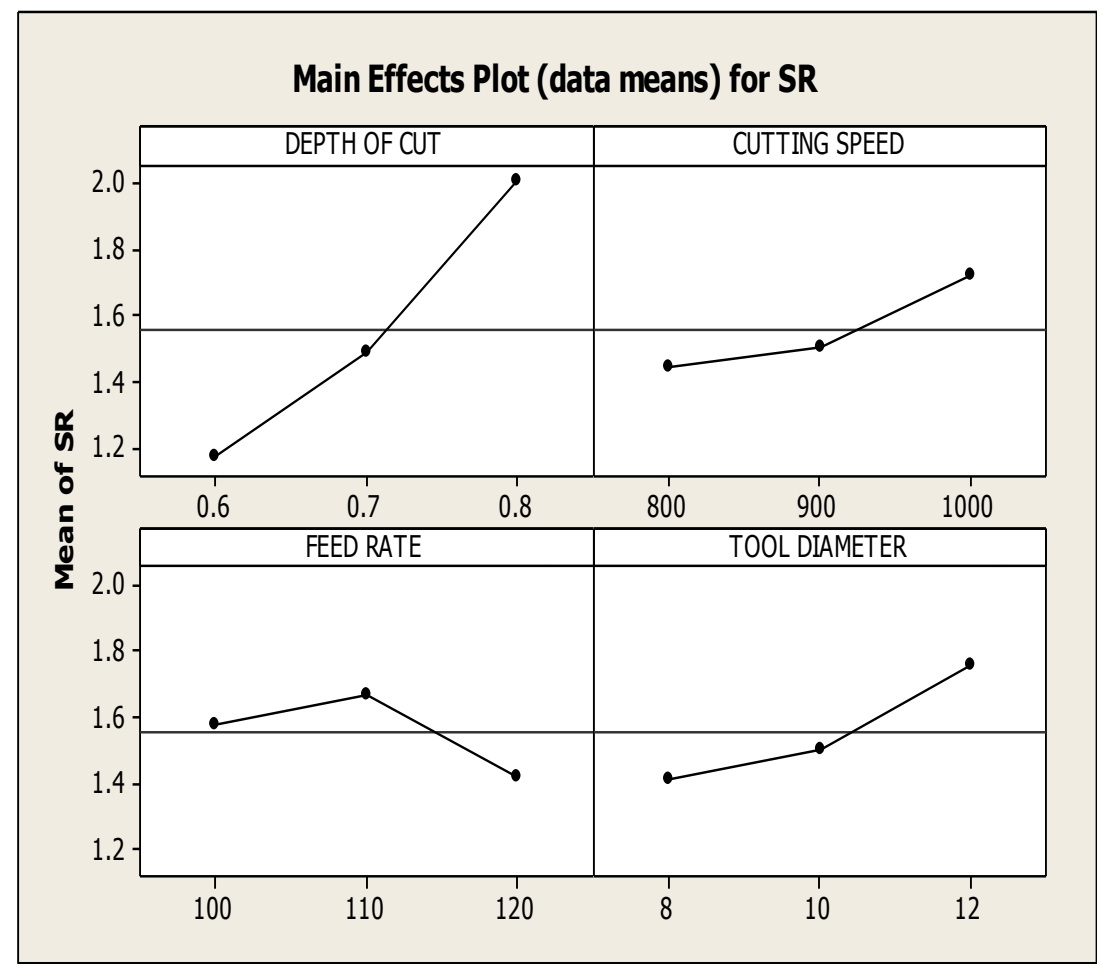

Main Effects Plot For SR

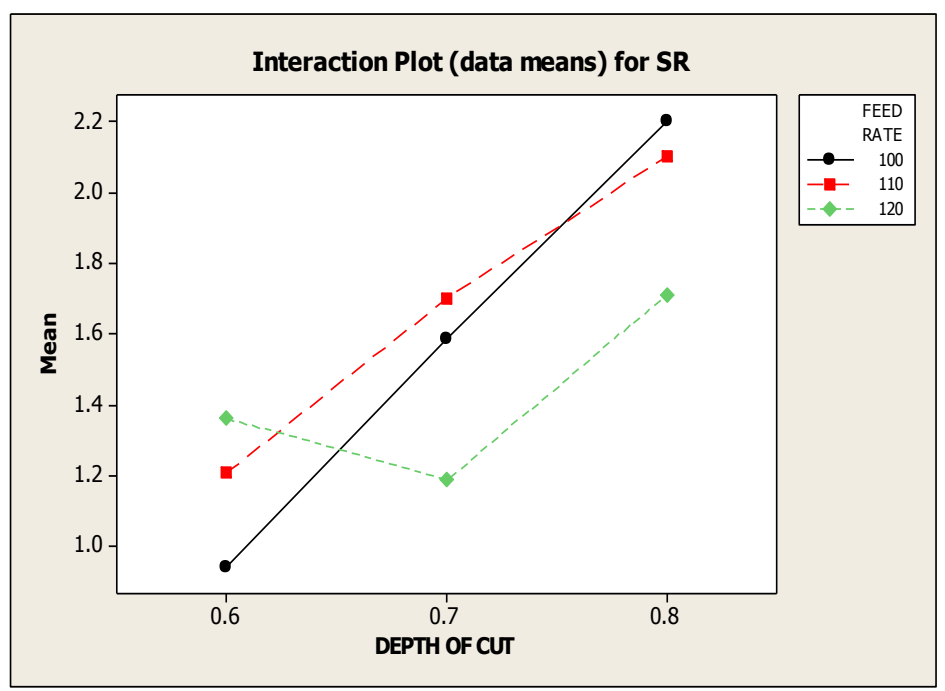

Interaction Plot For SR 


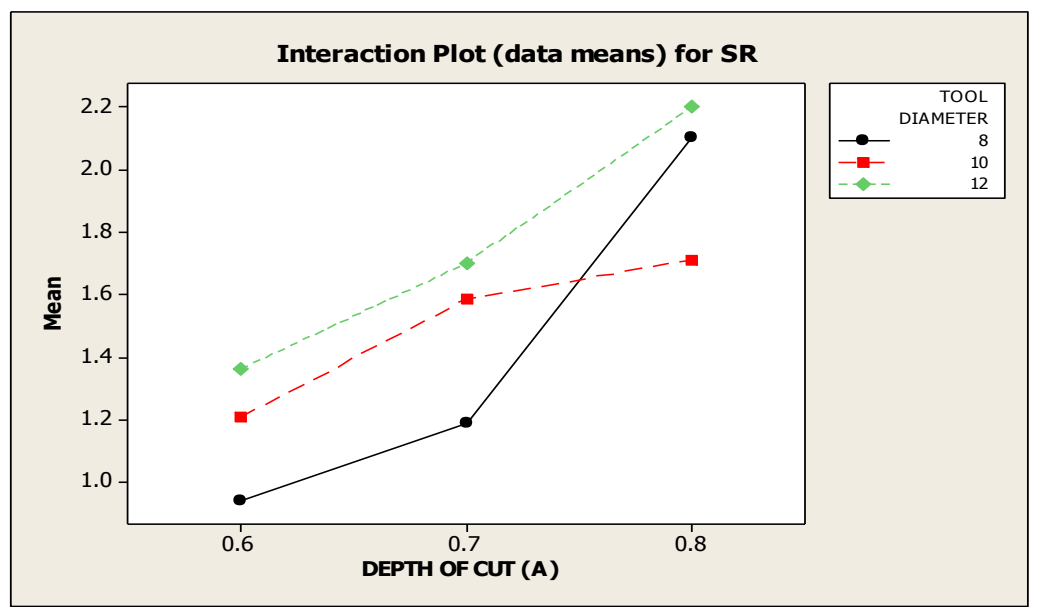

Interaction Plot For SR

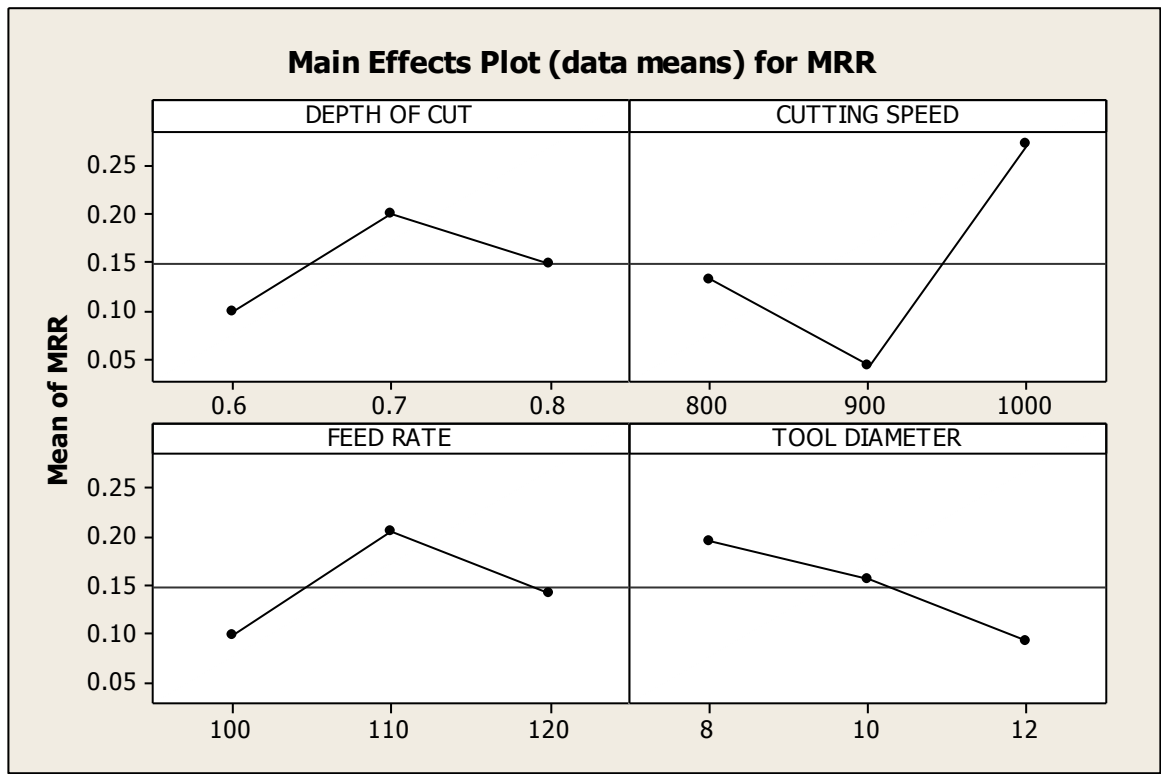

Main Effect Plot For MRR

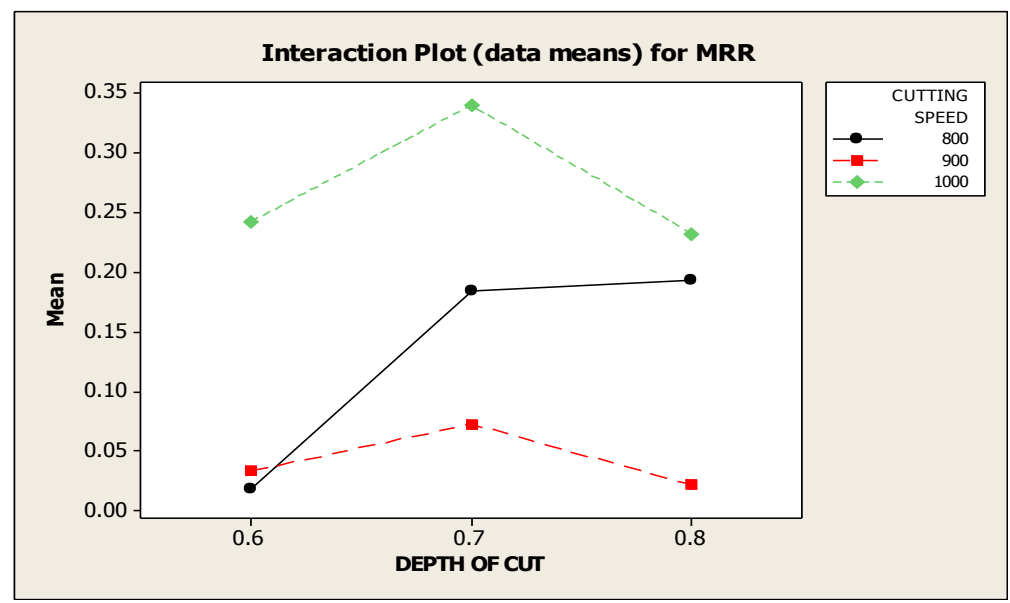




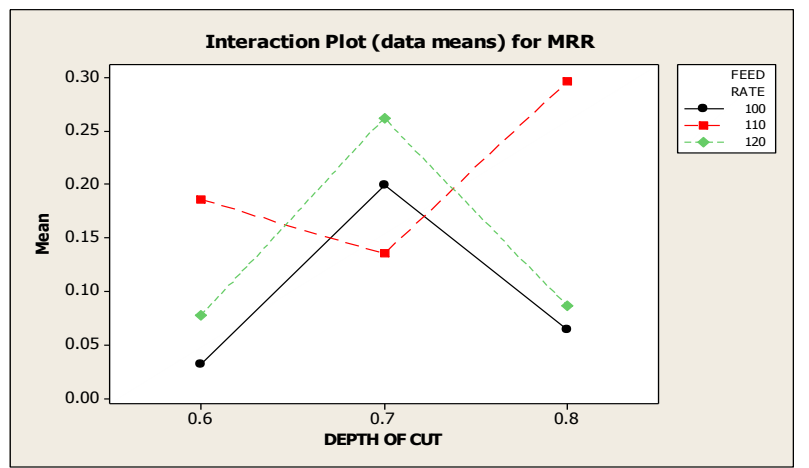

Interaction Plot for MRR

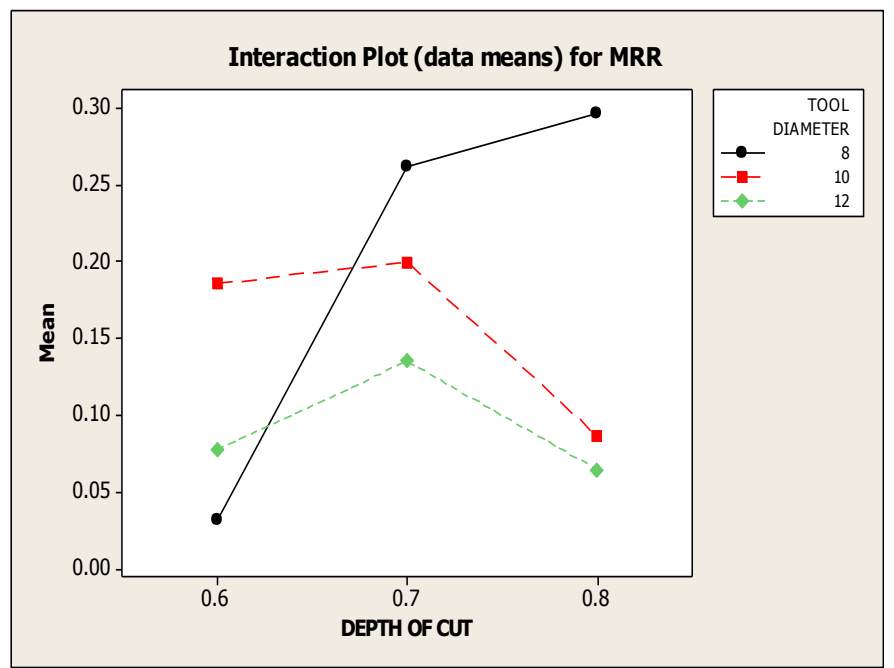

Interaction Plot for MRR

\section{Conclusion}

This experimental study described the development of process in terms of MRR and Surface finish, using Taguchi's $\mathrm{L}_{18}$ orthogonal array. It was fond that the $\mathrm{S} / \mathrm{N}$ ratio with Taguchi's parameter design is a simple, systematic, reliable and more efficient tool for optimizing multiple performance characteristics of CNC milling process parameters. Factors like depth of cut, feed rate, cutting speed, tool diameter and there interactions have been found to play a significant role in rough cutting operations for maximization of MRR and surface finish. Interestingly, the optimal levels of the selected control factors for both objectives differ widely. In order to optimize for both objectives, mathematical models are developed using the non-linear regression method.

Analysis of variance (ANOVA) is also employed to identify the level of importance of the machining parameters on the multiple performance characteristics namely material removal rate and surface roughness. Assumptions of ANOVA are tested using residual analysis. After careful testing, none of the assumptions was violated. ANOVA results showed that CUTTING SPEED AND FEED RATE are the powerful control parameters for the material removal rate and DEPTH OF CUT AND FEED RATE calculated as powerful factors for controlling the surface finish of Mild Steel. In case of MRR analysis, percent contribution for residual error is $4.166 \%$ is very small (less than $15 \%$ ), it is proved that no important factors were omitted during the experiment and there is no opportunity for the further improvement while surface roughness analysis result interprets that percent contribution of residual error is $-5 \%$ is small (less than $50 \%$ ), it is acceptable that no important factors were omitted during the experiment but there may be very small opportunity for the further improvement.

\section{REFERENCES-}

[1] Mr. Phillip J. Ross, Taguchi Technique for Quality Engineering (2005) 23-73, 91-256.

[2] Julie Z. Zhang, Joseph C. Chen, E. Daniel Kirby, Surface roughness optimization in an end-milling operation using the Taguchi design Method., Journal of Materials Processing Technology (2006) 233-238

[3] Dae kyun Baek, Tae jo ko, Hee Sool Kim, Optimization of feedrate in face milling operation using a surface roughness model, International Journal of machine Tools \& Mnufacturer (2001) 452-458

[4] Vijayan N. Nair, Bovas Abraham, Jock MacKay, John A. Nelder, George Box, Madhav S. Phadke, Raghu N. Kacker, Jerome Sacks, William J. Welch, Thomas J. Lorenzen, Anne C. Shoemaker, Kwok L. Tsui, James M. Lucas, Shin Taguchi, Raymond H. Myers, G. Geoffrey Vining, C. F. Jeff Wu, Tauchi's Parameter Design; A Panel Discussion, Technometric (1992) 133-146 
[5] John L. Yang \& Dr. Joseph C. Chen, A Systematic approach for identifying optimum Surface Roughness performance in EndMilling operations, Journal of Industrial Technology (2001) 3-6.

[6] J.A Ghani, I.A. Choudhary, H.H.Hassan, Application of Taguchi method in the optimization of end milling parameters, Journal of Materials processing technology (2004) 84-86

[7] Tzeng Yih-Fong, Jean Ming-Der, Dimensional quality optimization of high speed CNC milling process with dynamic quality characteristic, Robotics and Computer-Integrated Manufacturing (2005) 507-511

[8] Yuan Ning, M. Rahman, Y.S. Wong, Investigation of chip formation in high speed end milling, Journal of Materials processing technology (2001) 360-366

[9] M.G.Tuck, S.M. Lewis, J.I.L.Cottrell, Response Surface Methodology and Taguchi: A Quality improvement study from the milling industry, Jouranal of the Royal Statistical Society (1993)

[10] Yu-Hsuan Tsai, Joseph C. Chen, Shi-Jer Lou, An in-process recognition system based on neural network in end milling cutting operations, International Journal of machine Tools \& Manufacturer (1999)

[11] Meet Minitab 15 for windows (2007) 2.1-2.14, 3.1-3.12, 5.1-5.11, 8.1-8.11

[12] F-C Chen and Y-F Tzeng, Optimization of the volumetric accuracy of high-speed computer numerical control milling with dynamic quality characteristics, (2004)

[13] Julie Z. Zhang \& Joseph C. Chen, Tool condition monitoring in an end-milling operation based on the vibration signal collected through a microcontroller-based data acquisition system (2007)

[14] Tsao Chung-Chen \& Hocheng Hong, Comparison of the tool life of the tungsten carbides coated by multi-layer TiCN \& TiAlCN for end mills using the Taguchi method, Journal of Materials processing technology (2000)

[15] Madhav S. Phadke, Introduction to Robust Design (Taguchi Approach) (2001)

[16] Yih-Fong Tzeng \& Fu-chen CHEN, Optimization of the high speed CNC milling process using two-phase parameter design strategy by the Taguchi methods, JSME International Journal (2005) 775-781

[17] K.N. Ballantyne, R.A. van Oorschot, R.J. Mitchell, Reduce optimization time and effort: Taguchi experimental design methods, Forensic Science International: Genetics Supplement Series-1 (2007)

[18] Julie Z. Zhang \& Joseph C. Chen, Tool condition monitoring in an end-milling operation based on the vibration signal collected through a microcontroller-based data acquisition system (2007)

[19] George Box, Signal-to-Noise Ratios, Performance Criteria, and Transformations, Center for Quality and Productivity Improvement University of Wisconsin (1987)

[20] Age K. Smilde, General Introduction to Robustness, Laboratory for Analytical Chemistry, University of Amsterdam (2003)

[21] Ranjit K. Roy, Design of Experiments Using the Taguchi Approach: 16 Steps to Product and Process Improvement, Tachometric, (2001) 